\title{
The Effects of Heat Shock on the D-Values of Listeria monocytogenes on Selected Seafood Matrices
}

\author{
Michael V. Wood, Aswathy Sreedharan, Rachael Silverberg, Alina N. Balaguero, \\ Keith R. Schneider* \\ Department of Food Science and Human Nutrition, University of Florida, Gainesville, FL, USA \\ Email: ${ }^{*}$ keiths29@ufl.edu
}

Received 27 April 2015; accepted 1 August 2015; published 5 August 2015

Copyright (C) 2015 by authors and Scientific Research Publishing Inc.

This work is licensed under the Creative Commons Attribution International License (CC BY). http://creativecommons.org/licenses/by/4.0/

\section{(c) (i) Open Access}

\begin{abstract}
With more ready-to-eat foods and increased shelf-lives, prevention of Listeria monocytogenes contamination has become a necessity for the food industry. This study examined the effects of sublethal heat treatment on the decimal reduction time (D-values) of three L. monocytogenes serotypes $(1 / 2 a, 1 / 2 b, 4 c)$, and non-pathogenic $L$. innocua. The $D_{70}$ (D-value at $70^{\circ} \mathrm{C}$ ) values of heat-shocked (HS) and non-heat-shocked (NHS) Listeria grown in tryptic soy broth (TSB) were determined. The $D_{70}$ values of HS L. monocytogenes serotype $1 / 2$ a and $L$. innocua were significantly higher compared to NHS cultures, although by $48 \mathrm{~h}$, the values returned to NHS levels. When HS and NHS $1 / 2 a$ and $1 / 2 b$ were inoculated on crab meat and cooked shrimp, the $D_{70}$ values of HS cultures were at least 2 -fold higher, compared to when they were grown in TSB. This increase in heat resistance for the HS cultures may be attributed to the protective effect of the seafood matrix itself.
\end{abstract}

\section{Keywords}

Listeria monocytogenes, Ready-to-Eat Seafood, Heat Shock, D-Value

\section{Introduction}

In the past several decades, listeriosis, caused by the intracellular pathogen Listeria monocytogenes, has emerged as a major foodborne disease worldwide [1]-[3]. Of the eight current species in the genus Listeria, $L$. monocytogenes is the only one considered to be a foodborne pathogen in both humans and animals [4]. Listeria

*Corresponding author.

How to cite this paper: Wood, M.V., Sreedharan, A., Silverberg, R., Balaguero, A.N. and Schneider, K.R. (2015) The Effects of Heat Shock on the D-Values of Listeria monocytogenes on Selected Seafood Matrices Advances in Microbiology, 5, 580-585. http://dx.doi.org/10.4236/aim.2015.58060 
monocytogenes is divided into four distinct lineages each with unique genetic, phenotypic, and epidemiological characteristics. Lineages I and II are both associated with human disease, although most human listeriosis isolates are from lineage I. Lineage II strains are more frequently associated with sporadic listeriosis in humans, but are also associated with animal listeriosis. Lineage III and IV isolates are rarely found in foods or food-related environments, and have not been linked to human listeriosis [5]. Serovars 1/2a (lineage II), 1/2b and 4b (lineage I) account for $95 \%$ of human isolates [6].

Listeria has a potential to grow during cold storage due to its ability to proliferate at low temperatures ( 0 to $45^{\circ} \mathrm{C}$ ) and reduced oxygen levels, and is a problematic microorganism in the ready-to-eat (RTE) seafood industry. Several listeriosis outbreaks have been associated with seafood products [7]-[9], and Listeria spp. has been detected in several seafoods including fresh shrimp, crab meat, and smoked and fermented fish [3] [10] [11]. For RTE crustaceans, specifically cooked shrimp and canned crab meat, the risks are primarily linked to postprocess contamination [12]. Further, studies have shown that some cold-smoking processes do not completely kill L. monocytogenes [7]. The ability of smoked seafood to support the growth of Listeria during extended refrigeration temperatures [9] and the prior instances of outbreaks due to improper cooking times and temperatures during processing [7] accentuate the risk of Listeria contamination in RTE seafood.

Previous studies have shown that certain strains of $L$. monocytogenes exhibit a higher decimal reduction time (D-value) than others [13]. Differences in D-value, which is the time required to reduce a bacterial population by $90 \%$ (1.0 log unit) at a given temperature, can be attributed to various factors that contribute to pathogenicity [14]. The time of exposure to heat shock, the heating matrix, the condition of the L. monocytogenes culture, as well as the method used to recover the cells all have an effect on bacterial thermotolerance [15]. A previous study found that heat shocking $L$. monocytogenes at $42^{\circ} \mathrm{C}$ for $60 \mathrm{~min}$, followed by $60^{\circ} \mathrm{C}$ for various lengths of time resulted in approximately twice the $\mathrm{D}_{60}$-values compared to the non-heat shocked strain [16].

Several studies have investigated the effect of heat shock proteins on the D-values of certain strains of $L$. monocytogenes in certain types of food including dairy products, and ham [13] [16]. However, limited information exists regarding the relationship among the D-values of heat shocked and non-heat shocked Listeria spp. on RTE seafood. This study examined three serotypes of Listeria monocytogenes, 1/2a, 1/2b, and 4c, and one strain of Listeria innocua, a non-pathogenic species, to determine how the heat shocking affected D-values in both growth media and inoculated RTE seafood.

\section{Material and Methods}

\subsection{Bacterial Cultures}

Listeria monocytogenes cultures DUP-1039C (1/2a), DUP 1042B (1/2b) and 758453 (4c), originally isolated from smoked fish, a human isolate, and an animal isolate, respectively, were obtained from Dr. M. Weidman (Cornell University). Listeria innocua (ATCC 33090) was obtained from Dr. A. Wright (University of Florida). All four Listeria cultures were adapted to $350 \mathrm{mg} \cdot \mathrm{l}^{-1}$ nalidixic acid (NX), to eliminate contamination from background microflora during bacterial recovery and enumeration.

\subsection{Seafood Products}

Seafood matrices used in this study, crab meat (Callinectes sapidus), raw shrimp (Penaeus setiferus) and smoked salmon (Oncorhuncus goruscha) were commercially obtained from Northwest Seafood, Gainesville, FL. Crab meat and salmon were processed prior to purchase, whereas the raw shrimp was boiled for five min in tap water and refrigerated before the study. All seafood samples were cut into $10 \mathrm{~g}$ pieces.

\subsection{Heat Shocking of Listeria Cultures and Determination of $D_{70}$-Values}

Before heat shocking, two sets of Listeria cultures were grown in $10 \mathrm{ml}$ of tryptic soy broth (TSB) (Difco, Becton Dickinson, Sparks, MD)/NX $\left(50 \mathrm{mg} \cdot 1^{-1}\right)$ at $37^{\circ} \mathrm{C}$ overnight. Ten $\mu$ l of culture was transferred into fresh TSB for four consecutive days, and incubated at $37^{\circ} \mathrm{C}$ overnight. On day five, the bacterial cultures were centrifuged (4000 g for $20 \mathrm{~min}$ ), washed twice and resuspended in fresh Universal Pre-Enrichment Broth (UPB) (Difco, Becton Dickinson, Sparks, MD), to yield a concentration of $1.0 \times 10^{7} \mathrm{cfu} / \mathrm{ml}$. The cultures were initially exposed to a temperature of $50^{\circ} \mathrm{C}$ (simulating seafood temperature abuse conditions before processing), to evaluate the effect of sublethal heat treatment on the ability of Listeria strains to withstand lethal heat treatment at $70^{\circ} \mathrm{C}$. A 
subsequent thermal inactivation temperature of $70^{\circ} \mathrm{C}\left(\mathrm{D}_{70}\right.$-value $)$ was chosen based on typical temperatures recommended for many smoked seafood products [17]. The cultures were initially subjected to a temperature of $50^{\circ} \mathrm{C}$ by immersing the tubes in a waterbath for $60 \mathrm{~min}$ (Precision Series 280, Winchester, VA), and then given 15 - $30 \mathrm{~min}$ to recuperate [15]. One set of cultures were then incubated at room temperature (non-heat shocked), while the other (heat shocked) underwent the heat shocking protocol as described previously [15]. Briefly, the sublethally heated samples were placed into a waterbath (Precision Series 280, Winchester, VA), to heat up to $70^{\circ} \mathrm{C}$ for a total time of 5 and 5.5 min (with a $30 \mathrm{~s}$ warm up time). Heat shocked cultures, along with the corresponding non-heat shocked cultures, were removed every $30 \mathrm{~s}$ for $5 \mathrm{~min}$, and immediately placed on ice to stop any further heat inactivation. For enumeration, samples were serially diluted, pour plated on TSA, and incubated for 18 to $24 \mathrm{~h}$ at $37^{\circ} \mathrm{C}$. $\mathrm{D}_{70}$-value reversion was also calculated to evaluate the reversion of heat shocked cultures back to the non-heat shocked state. For this purpose, all HS and NHS cultures were inoculated into fresh TSB and incubated at $37^{\circ} \mathrm{C}$ for 24 and $48 \mathrm{~h}$, and $\mathrm{D}_{70}$ values were determined. An initial time point of $24 \mathrm{~h}$ for reversion studies represents the typical refrigerated storage times for food in households [18]. The experiment was repeated three times. The $\log _{10}$ values for cell counts were plotted against the time of exposure, and linear regression analysis was performed to calculate the $\mathrm{D}_{70}$-values. The data was statistically analyzed for significant differences by analysis of variance (ANOVA) and least squares difference test $(p \leq 0.05)$ using SAS (SAS Institute, Cary, NC, USA).

\subsection{Inoculation of Seafood Products and Determination of Listeria $\mathrm{D}_{70}$-Values}

Only the pathogenic strains, L. monocytogenes $1 / 2 \mathrm{a}$ and $1 / 2 \mathrm{~b}$ were included in studies for the determination of $\mathrm{D}_{70}$-values in seafood matrices. One hundred $\mu \mathrm{L}\left(1.0 \times 10^{6} \mathrm{cfu} / \mathrm{ml}\right)$ of heat shocked or non-heat shocked cultures were pipetted onto each $10 \mathrm{~g}$ seafood sample (cooked shrimp, crab meat, and smoked salmon). Samples incubated for $60 \mathrm{~min}$ at room temperature to achieve bacterial attachment. Seafood samples were placed into a Whirl-Pak ${ }^{\circledR}$ bag (NASCO, Fort Atkinson, WI), and placed into the Precision Series 280 waterbath and heated to an internal temperature of $70^{\circ} \mathrm{C}$ for $5 \mathrm{~min}$ (with a warm up time of $30 \mathrm{~s}$ ). The samples were removed every $30 \mathrm{~s}$ for $5 \mathrm{~min}$, and immediately placed on ice to stop any further heat inactivation. For Listeria enumeration, $90 \mathrm{ml}$ of PBS was added to each sample. Samples were serially diluted in PBS and pour-plated in TSA/NX. Plates were incubated at $37^{\circ} \mathrm{C}$ for 18 to $24 \mathrm{~h}$ before enumeration, and $\mathrm{D}_{70}$-values calculated as described previously.

\section{Results and Discussion}

\section{1. $\mathrm{D}_{70}$-Value Determination for Heat Shocked Cultures}

Heat shocking significantly increased the $\mathrm{D}_{70}$-values of $L$. monocytogenes $1 / 2 \mathrm{a}$ and $L$. innocua on day 0 (Table 1), but not that of L. monocytogenes $1 / 2 \mathrm{~b}$ and $4 \mathrm{c}$. By $48 \mathrm{~h}$, the $\mathrm{D}_{70}$-values of all HS Listeria cultures reverted back to that of NHS cultures (Table 1 ).

Results from this study revealed that $D_{70}$-values of $L$. monocytogenes $1 / 2$ a was much higher when subjected to heat shock conditions, compared to the $\mathrm{D}_{70}$-values of the non-heat shocked cultures. The $\mathrm{D}$-value reversion findings suggest that heat shocked $L$. monocytogenes cultures have the ability to recover from non-lethal heat treatments after $24 \mathrm{~h}$ once recultured into fresh enrichment broth. The increase in $\mathrm{D}_{70}$-values brought on by heat shocking fell significantly after $24 \mathrm{~h}$. This study showed that although sub-lethal thermal injury can induce heat

Table $1 . \mathrm{D}_{70}$-values (min) of Listeria cultures grown in tryptic soy broth, before and after heat shocking, on day $0,24 \mathrm{~h}$ and $48 \mathrm{~h}$.

\begin{tabular}{ccccc}
\hline \multirow{2}{*}{ Listeria culture } & \multicolumn{3}{c}{ Time and Treatment } \\
\cline { 2 - 5 } & NHS (Day 0) & HS (Day 0) & HS (24 h) & HS (48 h) \\
\hline $1 / 2 \mathrm{a}$ & $1.17 \pm 0.0 \mathrm{a}$ & $2.32 \pm 0.1 \mathrm{c}$ & $1.90 \pm 0.6 \mathrm{bc}$ & $1.46 \pm 0.1 \mathrm{ab}$ \\
$1 / 2 \mathrm{~b}$ & $1.31 \pm 0.2 \mathrm{a}$ & $1.47 \pm 0.2 \mathrm{a}$ & $0.99 \pm 0.1 \mathrm{a}$ & $1.11 \pm 0.1 \mathrm{a}$ \\
$4 \mathrm{c}$ & $1.29 \pm 0.1 \mathrm{a}$ & $1.56 \pm 0.1 \mathrm{a}$ & $1.11 \pm 0.0 \mathrm{a}$ & $1.3 \pm 0.0 \mathrm{a}$ \\
inпосиа & $0.82 \pm 1.1 \mathrm{a}$ & $2.5 \pm 0.3 \mathrm{~b}$ & $0.85 \pm 0.0 \mathrm{a}$ & $0.81 \pm 0.0 \mathrm{a}$ \\
\hline
\end{tabular}

\footnotetext{
*Values with different letters (a-b) in the same row differ significantly $(p<0.05)$.
} 
shock protein production and a subsequently increase $D_{70}$-values, these effects are lost after 24 - 48 h. Previous research has also shown that the protective responses induced by heat shocking are reversible [19] [20].

\section{2. $\mathrm{D}_{70}$-Values and Seafood}

A preliminary recovery study showed no statistical difference between inoculated and recovered levels of Listeria from any of the seafood matrices (Table 2). Additionally, a background microflora study showed that no organisms native to cooked shrimp, crab meat or smoked salmon had the ability to grow on the TSA/NX media used in this study (data not shown). The $\mathrm{D}_{70}$-values were calculated by using standard regression analysis coupled with a standard ANOVA analysis to determine statistical differences between the cultures. There was a significant increase in heat resistance ( $\geq 2$-fold) for the HS cultures (1/2a and $1 / 2 b)$ inoculated on cooked shrimp and crab meat. However, the $\mathrm{D}_{70}$-values of NHS and HS L. monocytogenes $1 / 2 \mathrm{a}$ and $1 / 2 \mathrm{~b}$ inoculated on smoked salmon were not significantly different (Table 3 ). The $\mathrm{D}_{70}$-value of HS L. monocytogenes $1 / 2 \mathrm{a}$ in TSB was 2.3 min, while the average $D_{70}$-value of the same organism inoculated on the experimental seafood matrices was 3.2 min. For the HS L. monocytogenes $1 / 2 \mathrm{~b}$, the $\mathrm{D}_{70}$-value in TSB was $1.5 \mathrm{~min}$, compared to $3.4 \mathrm{~min}$ for the average $\mathrm{D}_{70}$-values of HS L. monocytogenes $1 / 2 \mathrm{~b}$ on the tested seafood matrices.

When shrimp and crab meat were inoculated with heat shocked (HS) and non-heat shocked (NHS) pathogenic Listeria cultures, a two-fold or more increase in the $\mathrm{D}_{70}$-values were observed. This increase in heat resistance when compared to enrichment broth, could be attributed to the protective effect of the seafood matrix itself. The protective effect of the food matrix as observed in this study also concurs with another thermal inactivation study [13], in which the $\mathrm{D}_{60}$-values of $L$. monocytogenes inoculated in cream was two-fold higher than the $\mathrm{D}_{60^{-}}$ values in TSB. Further, the $\mathrm{D}_{60}$-values were also four times higher in the cultures inoculated on the seafood matrices than in TSB [21]. When comparing $\mathrm{D}_{70}$-values for each of the seafood matrices in this study, crab meat showed the most protective effect, showing a $\geq 2.5$-fold increase in $\mathrm{D}_{70}$-values compared to the values in TSB. The $\mathrm{D}_{70}$-values for cooked shrimp increased by $\geq 2$-fold, but that of smoked salmon increased only by $\geq 1.2$-fold. A previous study conducted by [21] also noted an increase in D-values associated with Listeria inoculated on seafood, and concluded that fat content had a significant role in the increased survivability. The results from this study however, do not suggest a direct correlation between the fat content and increased thermal resistance for

Table 2. Log reduction during the recovery of Listeria strains from inoculated seafood matrices.

\begin{tabular}{ccccc}
\hline & \multicolumn{2}{c}{ Seafood Matrix } & \multicolumn{2}{c}{ Listeria Culture } \\
\hline & $1 / 2 \mathrm{a}$ & $1 / 2 \mathrm{~b}$ & 4c & 0.08 \\
\hline Crab Meat & 0.01 & 0.09 & 0.17 & 0.19 \\
Smoked Salmon & 0.01 & 0.01 & 0.20 & 0.20 \\
Cooked Shrimp & 0.01 & 0.02 & 0.09 \\
\hline
\end{tabular}

Table 3. $\mathrm{D}_{70}$-values (min) of cooked shrimp, crab meat, and smoked salmon inoculated with NHS and HS L. monocytogenes.

\begin{tabular}{|c|c|c|c|}
\hline \multirow{2}{*}{ Seafood Matrix } & \multirow{2}{*}{ Listeria Culture } & \multicolumn{2}{|c|}{ Treatment } \\
\hline & & NHS & HS \\
\hline \multirow{2}{*}{ Cooked Shrimp } & $1 / 2 \mathrm{a}$ & $1.45 \pm 0.18 \mathrm{a}$ & $2.79 \pm 0.15 b$ \\
\hline & $1 / 2 b$ & $1.41 \pm 0.13 \mathrm{a}$ & $2.92 \pm 0.48 b$ \\
\hline \multirow{2}{*}{ Crab Meat } & $1 / 2 \mathrm{a}$ & $1.82 \pm 0.15 \mathrm{a}$ & $4.62 \pm 0.63 b$ \\
\hline & $1 / 2 b$ & $1.78 \pm 0.15 \mathrm{a}$ & $5.05 \pm 0.62 b$ \\
\hline \multirow{2}{*}{ Smoked Salmon } & $1 / 2 \mathrm{a}$ & $1.68 \pm 0.09 \mathrm{a}$ & $2.22 \pm 0.28 \mathrm{a}$ \\
\hline & $1 / 2 b$ & $1.92 \pm 0.16 \mathrm{a}$ & $2.22 \pm 0.28 \mathrm{a}$ \\
\hline
\end{tabular}

\footnotetext{
${ }^{*}$ Values with different letters $(a-b)$ in the same row differ significantly $(p<0.05)$.
} 
the matrices examined. Smoked salmon, which had the highest fat content in this study (8 $\mathrm{g}$ of fat per serving), yielded the smallest increase in $\mathrm{D}_{70}$-value. This observation is in accordance with a previous study on the heat resistance of $L$. monocytogenes in dairy products, which also concluded that that there was no correlation between fat content and heat resistance [13]. Besides fat content, other factors including water activity and osmotic stress could also have a protective effect yielding an increased thermal resistance [22]-[24]. A previous study by Farber [25] showed that when shrimp, crab and smoked salmon were stored at room temperatures for $6 \mathrm{~h} \mathrm{(simu-}$ lating temperature abuse conditions), the growth of $L$. monocytogenes was the lowest on smoked salmon, compared to cooked shrimp and crab. According to the study, the reduced growth of L. monocytogenes strain HPB 323 on smoked salmon may potentially be due the sensitivity of the pathogen to sodium chloride or other antimicrobial compounds present in smoke. The results from the current study also indicate that out of the three seafood matrices compared, smoked salmon had the least protective effect on L. monocytogenes. Antimicrobial effect of smoke on L. monocytogenes has also been reported by previously [26].

\section{Conclusion}

The results from this study indicate that $\mathrm{D}_{70}$-values of HS L. monocytogenes $1 / 2 \mathrm{a}$ and $L$. innocua strains are significantly higher when compared to NHS cultures. However, after 24 - 48 h, a minimum refrigeration period for food before being reheated and consumed (NSF International 2015), the $\mathrm{D}_{70}$-values noted in this study reverted to levels equivalent to those seen prior to heat shocking. Thus, the cross-protection attributed to these injured microorganisms may not be a factor in the virulence of $L$. monocytogenes in food stored long. The higher $\mathrm{D}_{70^{-}}$ values of $L$. monocytogenes on contaminated cooked shrimp and crab meat suggest a greater protection for the pathogen from the detrimental effects of heat. Thus, contaminated RTE seafood may need to be heated for a longer time to inactivate $L$. monocytogenes.

\section{References}

[1] Centers for Disease Control and Prevention [CDC] (2015) Multistate Outbreak of Listeriosis Linked to Blue Bell Creameries Products. http://www.cdc.gov/listeria/outbreaks/ice-cream-03-15/index.html http://www.cdc.gov/listeria/pdf/listeria-annual-summary-2010-508c.pdf

[2] de Noordhout, C.M., Devleesschauwer, B., Angulo, F.J., Verbeke, G., Haagsma, J., Kirk, M., Havelaar, A. and Speybroeck, N. (2014) The Global Burden of Listeriosis: A Systematic Review and Meta-Analysis. The Lancet Infectious Diseases, 14, 1073-1082. http://dx.doi.org/10.1016/S1473-3099(14)70870-9

[3] Norhana, M.N.W., Poole, S.E., Deeth, H.C. and Dykes, G.A. (2010) Prevalence, Persistence and Control of Salmonella and Listeria in Shrimp and Shrimp Products, a Review. Food Control, 21, 343-361. http://dx.doi.org/10.1016/i.foodcont.2009.06.020

[4] Jianshun, C., Fang, C., Zhu, N., Lv, Y., Cheng, C., Bei, Y., Zheng, T. and Fand, W. (2012) Genetic Organization of ascB-dapE Internalin Cluster Serves as a Potential Marker for Listeria monocytogenes Sublineages IIA, IIB, and IIC. Journal of Microbiology and Biotechnology, 22, 575-584. http://dx.doi.org/10.4014/jmb.1110.10056

[5] Orsi, R.H., den Bakker, H.C. and Wiedmann, M. (2011) Listeria monocytogenes Lineages: Genomics, Evolution, Ecology, and Phenotypic Characteristics. International Journal of Medical Microbiology, 301, 79-96. http://dx.doi.org/10.1016/j.ijmm.2010.05.002

[6] Rocourt, J. (1999) The Genus Listeria and Listeria monocytogenes: Phylogenetic Position, Taxonomy and Identification. In: Ryser, E.T. and Marth, E.H., Eds., Listeria, Listeriosis and Food Safety, 2nd Edition, Marcel Dekker, New York, 1-20.

[7] Guyer, S. and Jemmi, T. (1991) Behavior of Listeria monocytogenes during Fabrication and Storage of Experimentally Contaminated Smoked Salmon. Applications of Environmental Microbiology, 57, 1523-1527.

[8] Riedo, F.X., Pinner, R.W., Tosca, M.L., Cartter, M.L., Graves, L.M., Reeves, M.W., Weaver, R.E., Plikaytis, B.D. and Broome, C.V. (1994) A Point-Source Foodborne Listeriosis Outbreak: Documented Incubation Period and Possible Mild Illness. Journal of Infectious Diseases, 170, 693-696. http://dx.doi.org/10.1093/infdis/170.3.693

[9] Tham, W., Ericsson, H., Loncarevic, S., Unnerstad, H. and Danielsson-Tham, M.L. (2000). Lessons from an Outbreak of Listeriosis Related to Vacuum-Packaged Gravid and Cold-Smoked Fish. International Journal of Food Microbiology, 62, 173-175. http://dx.doi.org/10.1016/S0168-1605(00)00332-9

[10] Dillon, R.M. and Patel, T.R. (1992) Listeria in Seafood: A Review. Journal of Food Protection, 55, 1009-1015.

[11] McCarthy, S.A. (1996) Incidence and Survival of Listeria monocytogenes in Ready-to-Eat Seafood Products. Journal 
of Food Protection, 60, 372-376.

[12] FDA, US Food and Drug Administration (2003) Quantitative Assessment of the Relative Risk to Public Health from Foodborne Listeria monocytogenes among Selected Categories of Ready-to-Eat Foods. http://www.fda.gov/food/foodscienceresearch/risksafetyassessment/ucm183966.htm

[13] Casadei, M.A., de Matos, R.E., Harrison, S.T. and Gaze, J.E. (1998) Heat Resistance of Listeria monocytogenes in Dairy Products as Affected by the Growth Medium. Journal of Applied Microbiology, 84, 234-239. http://dx.doi.org/10.1046/j.1365-2672.1998.00334.x

[14] Lindquist, S. (1986) The Heat-Shock Response. Annual Review of Biochemistry, 55, 389-393. http://dx.doi.org/10.1146/annurev.bi.55.070186.005443

[15] Zhao, T. and Doyle, M.P. (2001) Evaluation of Universal Preenrichment Broth for Growth of Heat-Injured Pathogens. Journal of Food Protection, 64, 1751-1755.

[16] Carlier, V., Augustin, J.C. and Rozier, J. (1996) Heat Resistance of Listeria monocytogenes (Phagovar 2389/2425/ 3274/2671/47/108/340): D- and Z-Values in Ham. Journal of Food Protection, 59, 588-591.

[17] Venugopal, V. (2005) Seafood Processing: Value Addition Techniques. In: Venugopal, V., Ed., Seafood Processing: Adding Value through Quick Freezing, Retortable Packaging and Cook-Chilling, CRC Press, Boca Raton, 341-377. http://dx.doi.org/10.1201/9781420027396

[18] NSF International (2015) NSF Food Behavior Survey. http://www.nsf.org/consumer-resources/studies-articles/surveys/food-safety-behavior-survey/

[19] Pirie, J.H.H. (1940) The Genus Listerella. Science, 91, 383.

[20] Bunning, V.K., Crawford, R.G., Tierney, J.T. and Peeler, J.T. (1990) Thermotolerance of Listeria monocytogenes and Salmonella typhimurium after Sublethal Heat Shock. Applied and Environmental Microbiology, 56, 3216-3219.

[21] Ben Embarek, P.K. and Huss, H.H. (1993) Heat Resistance of Listeria monocytogenes in Vacuum Packaged Pasteurized Fish Fillets. International Journal of Food Microbiology, 20, 85-95. http://dx.doi.org/10.1016/0168-1605(93)90096-Y

[22] Fernandez, A., Lopez, M., Bernardo, A., Condon, S. and Raso, J. (2007) Modelling Thermal Inactivation of Listeria monocytogenes in Sucrose Solutions of Various Water Activities. Food Microbiology, 24, 372-379. http://dx.doi.org/10.1016/j.fm.2006.07.017

[23] Jorgensen, F., Stephens, P.J. and Knochel, S. (1995) The Effect of Osmotic Shock and Subsequent Adaptation on the Thermotolerance and Cell Morphology of Listeria monocytogenes. Applied Microbiology, 79, 274-281.

[24] Sumner, S.S., Sandros, T.M., Harmon, M.C., Scott, V.N. and Bernard, D.T. (1991) Heat Resistance of Salmonella typhimurium and Listeria monocytogenes in Sucrose Solutions of Various Water Activities. Journal of Food Science, 56, 1741-1744. http://dx.doi.org/10.1111/j.1365-2621.1991.tb08684.x

[25] Farber, J.M. (1991) Listeria monocytogenes in Fish Products. Journal of Food Protection, 54, 922-934.

[26] Messina, M.C., Ahmad, H.A., Marchello, J.A., Gerba, C.P. and Paquette, M.W. (1988) Effect of Liquid Smoke on Listeria monocytogenes. Journal of Food Protection, 51, 629-631. 